\title{
Evaluation of the extent of integration of humanoids in tackling social-economic challenges confronting the Africa continent
}

\begin{abstract}
This paper, gives a background of the social economic challenges facing the African continents, there fundamental causes and the measures currently in place in tackling this issues. It further present an insight to one of the approach been adopted by western countries such as the use of robots specifically Humanoids in ameliorating these challenges. Furthermore, it attempted to present an overview of the extent to which the Africa Continent has been able to adopt and integrate Humanoids for the same purpose. It then presents some of the setbacks to the full integration of Humanoids in the region and makes suggestion on the way forward.
\end{abstract}

Keywords: Africa, artificial intelligence, humanoids, machine learning, robotics
Volume 4 Issue 2 - 2018

\author{
Ajibo Augustine C, Ogbuka Maryrose C, \\ Udechukwu Felix $C$ \\ Department of Electronic Engineering, University of Nigeria \\ Nsukka, Nigeria \\ Correspondence: Ajibo Augustine C, Department of \\ Electronic Engineering, University of Nigeria Nsukka, Nigeria, \\ Email augustine.ajibo@unn.edu.ng
}

Received: December 30, 2017 | Published: March 23, 2018

\section{Introduction}

The sustenance and growth of any nation, depends critically and essentially on her level of development. A country seen as developed when is able to provide qualitative life for her citizenry. ${ }^{1}$ The African continent amidst her huge human, material and natural resources has been battling with the problems of development even after many of the countries in the region has gained her independence. Economic Researchers have overtime attributed this challenge to factors like: Inadequate executive capacity responsible for the formulation and implementation of developmental policies, Lack of good governance, High level of corruption and indiscipline and mono-economic base of most countries in the region. However, European and Asian countries experience enviable growth and development patterns attributable to : the development of agricultural sector, improved mass education of her citizenry, development of indigenous industries, export oriented strategy, disciplined leadership style, existence of efficient bureaucracy human resources development, encouragement of a dynamic private sector working in cooperation with the government towards a society-wide vision of development, institutional capacity building and attention to the problems of governance, consistency and policy stability. ${ }^{2-4}$ It is said that human and technology go hand in hand. There have been rapid advances in technology in most western world and this has led to a surge of both government and public interest in automation and robotics. ${ }^{5-7}$ Robotics, which is an out spring from Mechatronics, has overtime evolved due to advances in Control Technologies and Computer Science. The rapid progress in innovative Sensors and Actuators technologies and breakthroughs in Data Science specifically in the area of Artificial Intelligence (AI) and Machine Learning (ML) have resulted in the development of Intelligent Robots. ${ }^{8}$ It is believed that the future would be a place where man and robots cohabit for the realization of man's all round needs. In recent times, various kinds of practical assistive robots have been developed to suits mans need in different fields. For instance in the medical and welfare fields, exoskeleton power assist robots, assistive manipulators, robotic beds, and intelligent wheelchairs have been developed to cater for critical challenges in these areas by providing direct and physical assist either disabled people or their helpers. ${ }^{9}$ Several robots have been developed for the Industries, Educational sector, Aviation and Transport sectors, Commercial sectors etc. The quest to build a human like robot led to the development of Humanoids. This kind of robots which is seen as the most advanced creature of Man is envisioned to be the most ideal assistants and companion of human beings. This set of robots can interact with man and carry out functions independently. Humanoids are believed to be more efficient and effective than man in some areas as they only a stable source of power to function. As such they can be deployed to undertaking physically and mentally challenging routines. ${ }^{10}$ Humans in different situations need companion at different point in time. Cases abound where man is not able to get companion or counsel from other humans immediately when sort. This could be due to the fact that they are far away off/out of communication or they are no more. Thus, humanoids could fit in to meet this need as they communicate in a socially intelligent manner, recognizes and can learn human behaviors and psychology. ${ }^{11-13}$ Many western countries have embraces the use of Automation and Robotics in ameliorating her development challenges as: Robots have increased their productivity and competitiveness, increased productivity has lead to increased demand thus creating new job opportunities. Automation also has led overall to an increase in labor demand and positive impact on wages, and Robots complement and augment labor. Currently, the level of integration of these intelligent robots in both domestic and public environments of most third world countries like Africa has been very insignificant. This to an extent could be attributed to the Government polices; Religious and Cultural believe of the people. Most of the robots in the regions are mostly industrial .Very few available robots in the region are humanoids. Many have not been really integrated into public place and private homes. This is due to the fact that majority are of them are not built to adapt properly with the culture, religion and psychology of the people in the region. As such people find it difficult to accept these robots as companions and helpers in either homes, schools, hospitals, shopping malls, airports and other public places. If Africa is to fully embrace humanoids, there is an urgent need to build humanoids that are adaptive to the cultural, religious and psychological inclination of people in this region. To be able realize this; there is great need for more advanced research cognitive science/reasoning, adaptive learning and human 
psychology. This is also need for interdisciplinary research on the people of Africa to understand their psychology, way of life, music, dancing, greeting etc. Also there is great need for friendly government policies in this regard. Policies that will encourage youth participate in the development of cultural and religious friendly humanoid for meeting the need of their immediate environment. By so doing there will be a reduction in the level of unemployment and improved living condition for people in the region.

\section{Conclusion}

The African continent amidst her huge human, material and natural resources has been battling with the problems of development. Many western continent have embraces the used of Automation and Robotics in ameliorating her development challenges as it is believed that: Robots increase productivity and competitiveness, increased productivity can lead to increased demand, creating new job opportunities, Automation has led overall to an increase in labor demand and positive impact on wages, and Robots complement and augment labor. It is speculated that future will be robots and humans working together. However the degree of integration of this technology in the African society has been almost insignificant. This is greatly attributable to government policies, religious and cultural believes of the people in the region. If Africa is going to join the rest of the world in her strive for development, it need a serious policy reform that will pave way for constructive technologies that will bring about the needed development in the region.

\section{Acknowledgements}

None.

\section{Conflict of interest}

The authors declare there is no conflict of interest.

\section{References}

1. Lawal T, Oluwatoyin A. National development in Nigeria: Issues, challenges and prospects. Public Adm. 2011;3:237-241.
2. Farah I, Kiamba S, Mazongo K. Major challenges facing Africa in the 21 . Africa (Lond); 2011 July 14-17; Berlin. p.1-10.

3. Mahzoon H, Yuichiro Yoshikawa, Hiroshi Ishiguro. Social Skill Acquisition Model through Face-to-Face Interaction: Local Contingency for Open-Ended Development. Computational Intelligent. 2016;3:1-14.

4. Ndulu B. Challenges of African growth. The World Bank, USA. 2007. p. $1-221$.

5. Middle Ages, The impact of robotics on future societies. p. 1-9.

6. Guy Michaels, Georg Graetz. Estimating the impact of robots on productivity and employment. 2015.

7. Dirican C. The impacts of robotics, artificial intelligence on business and economics. Procedia-Soc Behav Sci. 2015;195:564-573.

8. Ollero A, Boverie S, Goodall R, et al. Mechatronics, robotics and components for automation and control IFAC milestone report. Annual Reviews in Control. 2006;30(1):41-54.

9. Vukobratovi M. Humanoid robotics-past, present state, future-. SerbianHungarian Joint Symposium on Intelligent Systems; 2006. p.1-19.

10. Majgaard G. Humanoid Robots in the Classroom. IADIS Int J. 13(1):7286.

11. Mahzoon H, Yoshikawa Y, Ishiguro H. Developmental robot with ostensive cue sensitive learning for real-world interaction based on local contingency evaluation. Development and Learning and Epigenetic Robotics IEEE; 2016 september 19-22; France.

12. Cooney MD, Nishio S, Ishiguro H. Recognizing affection for a touchbased interaction with a humanoid robot. IEEE Int Conf Intell Robot Syst; 2012. p. 1420-1427.

13. Yoshikawa M, Matsumoto Y, Sumitani M, et al. Development of an android robot for psychological support in medical and welfare fields. IEEE Int Conf Robot Biomimetics, ROBIO; 2011. p. 2378-2383. 